\title{
Decision Support in Assessing the Sustainable Use of Forests and Other Natural Resources - A Comparative Review
}

\author{
Tanja Myllyviita ${ }^{*}$, Teppo Hujala $^{2}$, Annika Kangas ${ }^{3}$ and Pekka Leskinen ${ }^{1}$
}

${ }^{I}$ Finnish Environment Institute, Research Programme for Production and Consumption, Yliopistonkatu 7 (Natura), P.O. Box 111, FI-80101 Joensuu, Finland

${ }^{2}$ Finnish Forest Research Institute, P.O. Box 68, FI-80101 Joensuu, Finland

${ }^{3}$ University of Helsinki, Department of Forest Sciences, P.O. Box 27, FI-00014 University of Helsinki, Finland

\begin{abstract}
Various decision support methods are used to support the sustainable use of natural resources, but there is little evidence about these methods' actual performances. In this study, 35 carefully selected papers assessing the sustainable use of natural resources were evaluated. The evaluated papers utilized one of the following methods: optimization, costbenefit analysis (CBA) and monetary valuation methods, multi-criteria decision analysis (MCDA) or hybrid approaches. Each method supported sustainability in a different manner. Optimization and CBA case studies rarely involved stakeholders and social sustainability was less processed. Monetary valuation case studies showed a regular participation of the general public, but in a passive role. Experts and stakeholders with an active role were typical participants in MCDA and hybrid case studies. Internationally and nationally defined indicators of sustainability were scarcely used because indicators were frequently defined by stakeholders or the authors of the studied papers. It was presumed that international and national indicators were unsuitable for local use. Sustainability indicators typically took both the quantitative and qualitative form, including gaps and uncertainties. MCDA could be a suitable method for assessing sustainability because it has no strict requirements on the form of the data, and the participation of stakeholders is comprehensive. For the problem structuring phase, however, MCDA might not provide efficient tools. The ideal method for assessing the sustainable use of natural resources could be a hybrid of two methods with different approaches: qualitative methods could be used in the problem structuring process, whereas quantitative methods could be used when priorities and thresholds are assessed.
\end{abstract}

Keywords: Criteria and indicators, cost-benefit analysis, decision support, indicator approach, monetary valuation, multicriteria decision analysis, optimization, sustainable forestry.

\section{INTRODUCTION}

Sustainable forest management (SFM) has become an important topic in forestry since the principles of SFM were defined in 1992 at the United Nations (UN) Conference on Environment and Development in Rio, Brazil [1]. Sustainability includes economic, ecological and social dimensions, which can be competing or exclusive [2]. The participation of the general public is also crucial in sustainable management of forest and other natural resources as well $[3,4]$. Thus, management of natural resources is challenged by the demands of nemurous stakeholders and perspectives, posing challenges for decision-making. In forest management, decision-making has frequently culminated in conflict. These conflict situations can often be because of stakeholder different interests [5] or different understandings of what sustainability means.

There is no universally accepted definition for SFM, although it is often considered an extension of Bruntland's concept of sustainable development [6]. For centuries,

Address correspondence to this author at the Finnish Environment Institute, Research Programme for Production and Consumption, Yliopistonkatu 7 (Natura), P.O. Box 111, FI-80101 Joensuu, Finland; Tel + 358400148 808; E-mail: tanja.myllyviita@ymparisto.fi sustainability has been described in forestry under the term "sustained yield" [7], with the main attention on securing future harvests. Although sustainability includes social, economic, ecological and cultural aspects, occasionally one or more dimensions of sustainability are neglected in the decision-making process [8]. Over the past few decades, however, biodiversity loss, climate change, chemicalization and deforestation have gradually demanded more and more attention of both scientists and the general public. Consequently, ecological sustainability is becoming an established concept. Social sustainability is the most disregarded dimension of sustainability because of difficulties with defining and measuring the concept. Over recent decades, a range of institutions has committed principles of sustainability including social, economic and ecological values.

One of the most applied ways of assessing sustainability is the indicator approach. Indicators can provide useful information on the status and trends of sustainable development and such information can then be used by decision-makers. Sustainable development indicators (SDI) include economic, ecologic and social dimensions. Experts from several fields have participated in numerous meetings to compile lists of criteria and indicators (C\&I). Lists of potential indicators have been compiled regionally, 
nationally and internationally, with immense investments of time and effort [9]. The conceptual use of these indicators as political tools is frequent, but their utilization in decisionmaking is limited [9]. In particular, defining the actual decision problem can be ignored if the process is strongly indicator-oriented, because the majority of time and effort is used to define suitable indicators instead of considering casespecific contextual decision alternatives that could foster sustainability. Decision-making is frequently unable to reach consensus or define actual decision alternatives and the preferences of the stakeholders, if there are no formal tools to assist the process.

Various decision support systems (DSS) and other less formal methods can provide support and structure to the decision process while assessing indicators and sustainability. Decisions are often made without the assistance of the methods, but when the number of decisionmakers and the impact of the decisions increases, the benefits of the methods become apparent. According to Martins and Borges [10], a multi-criteria decision-making process includes three stages: (1) problem identification, (2) problem modelling and (3) problem solving. Problem identification includes identifying goals and objectives, management alternatives, related policies, resources, conflicts and interactions. The stakeholders are selected and their perceptions evaluated. Problem modelling includes building a model to represent the relationships between management alternatives and outcomes of interest and the management policy scenarios. In the problem solving phase, management alternatives are prioritized. Belton and Stewart [11] include defining the alternatives into the model building phase. The last phase of the process is the development of an action plan [11]. There can be iteration both between and within the phases of the decision-making process, and it can also be influenced by several factors e.g. decision-makers, clients, sponsors, saboteurs and the facilitators [11].

The tools and methods assisting decision-making can be divided into qualitative and quantitative methods. Quantitative methods (or "hard OR") focus on generating quantified results. Qualitative methods (or "soft OR"), on the contrary, concentrate on cognitive and verbal concepts and structuring the problem. However, the methods often comprise both qualitative and quantitative features. The way of sequencing or mixing hard and soft components essentially affects the abilities of any method to grasp the various aspects of the decision problem at hand. Decision problems can also be divided into continuous, discrete and cases with several decision-makers [12]. Different methods are suitable for different problems.

Quantitative methods such as optimization have a long tradition in forest management. Optimization helps evaluate different plans of actions by maximizing or minimizing certain objectives in a continuous setting. A typical optimization application in forestry is defining the optimal harvest cycle. Another example of quantitative methods is the family of cost-benefit analysis (CBA) that evaluates decisions based on their costs and benefits, including benefits from non-market products and services. The estimates of those benefits are based on subjective preferences. Although economists have been criticized for putting a 'price tag' on nature, as Verbič and Slabe-Erker
[13] state determining monetary values can be useful if they ensure that environmental impacts are given weight or concrete consideration in the decision-making process. In addition, if those non-market benefits of forests were not expressed in monetary terms in the evaluations, they might be omitted or even wrongly attributed to the other sectors of economy [14]. The third example of quantitative methods is the multi-criteria decision analysis (MCDA) approach that is widely applied in supporting decision-making in forestry and the use of other natural resources in discrete settings. At best, MCDA supports participation by measuring the preferences of stakeholders and giving them opportunities to influence and learn. Nevertheless, MCDA has also been criticized for its highly technical features [15]. In addition, MCDA might not support the participation of stakeholders if its main focus is on generating consensus and the diversity of viewpoints is being ignored [16].

Qualitative methods can improve the participation and learning process [17] and assist stakeholders and the facilitator to reveal relevant factors, perspectives and issues during the problem structuring phase. This is particularly relevant in messy decisions with large datasets, which is typically the case in strategic large-scale forestry decisionmaking. Nevertheless, qualitative methods give little emphasis on generating solutions because the main focus is on structuring the problem [18].

Because any single method might not be the best alternative for assessing the sustainable use of natural resources, the employment of hybrid approaches has also been suggested. Hybrid methods can be based on two or more methods that have dominant quantitative features, e.g., MCDA and optimization [19, 20], but the hybrid methods often combine quantitative and qualitative methods. The benefits of the mixed hybrid methods are significant in ambiguous situations with conflicting goals of different stakeholders, when the relevant criteria and the decision alternatives might be difficult to find [11]. Hybrid methods support a comprehensive problem structuring and enhance participation without neglecting solution orientation $[10,21$ 24].

The participation of different stakeholders is connected to social sustainability, which is often mentioned as a requirement to achieve sustainable results. Stakeholders participating in the decision process include policymakers, planners and administrators in governmental and other organizations [25]. Selecting participants is a significant task because different stakeholders can produce different outcomes, and correspondingly the mechanism used to select stakeholders should be transparent [26, 27]. The role and power the participants are given can be substantial. Arnstein [28] described a "ladder of participation", a continuum of increasing stakeholder involvement from the passive distribution of information to active engagement. On the first steps of the ladder, participants are used more as "rubber stamps" than active participants. On the highest steps of the ladder, participation becomes more negotiating and the participants' power increases. However, a successful level of participation also depends on the objectives of the participation [29], and participants can also have varying conceptions of proper participation $[30,31]$. 
Decision-making processes are frequently driven by experts and authoritative stakeholders, whereas less emphasis is given on the preferences of the general public [32]. Depending on the decision problem in question, engaging the general public into the process is expected to provide more generally acceptable and transparent results [32]. Stakeholders usually include members with little or no education in modelling or management of natural resources, and consequently they might be unable to understand complicated methods used during the decision process [17]. Models constructed by experts are often a "black-box" to the general public, causing distrust among stakeholders [33]. Stakeholders can also be reluctant to change their minds in situations where results produced using unfamiliar methods conflict with their intuitive or unaided decisions [34]. Because of these difficulties in understanding the methods $[35,36]$, decision-making models should be more comprehensible.

Various DSS and other methods have been used to assess the sustainable use of forests and other natural resources without evaluating how these methods actually succeed in advancing the different dimensions of sustainable development. Additionally, how the application of different methods affects the success of stakeholders' participation is not been assessed. The general aim of this paper is to review and compare the characteristics of different methods of supporting the sustainable use of natural resources. The characteristics of the methods will be evaluated based on criteria related to a successful decision process that have been selected based on the challenges reviewed earlier in this paper: 1) the utilization of C\&I; 2) the participation of stakeholders, experts and the general public; 3 ) the type of participation in terms of its activeness or passiveness; 4) the inclusion of ecological, economic and social sustainability; and 5) problem structuring from the perspective of its technical or problem orientation. This study will also explore the utilization of international, national and regional indicator lists as well as the different stakeholder groups' roles and occurrences in the participation processes when employing different decision support methods. The data analyzed in this paper include a sample of case studies related to the aim of supporting the sustainable use of natural resources.

The rest of this paper is organized as follows. In Section 2, a brief review of the methods applied to support the sustainable use of natural resources is given. In Section 3, the capabilities of the different methods used to process sustainability are evaluated. In Section 4, the results of these methods' abilities to support decision-making are discussed in context of sustainability and based on information obtained from case studies. The characteristics of an "ideal" method to support the sustainable use of natural resources are also considered.

\section{DIFFERENT METHODS TO SUPPORT THE SUSTAINABLE USE OF NATURAL RESOURCES}

For review and comparison, a sample of 35 case studies was selected (Table 1). The selected case studies comprise various families of methods for supporting the sustainable use of natural resources. In this section, those methods are briefly introduced and some examples of their practical utilization are presented. A more comprehensive review on optimization methods in forest planning is provided by Baskent and Keles [37], CBA in environmental policymaking by Hanley [38], CBA in forestry by Price [39], MCDA and goal programming (GP) assessing forestry by Diaz-Balteiro and Romero [40] and MCDA in managing forests and other natural resources by Mendoza and Martins [18].

\section{(Multi-Objective) Optimization}

(Multi-objective) optimization refers to choosing the optimal of an infinite number of alternatives with respect to objectives [41]. Generally, the best alternative is the most profitable one in economic terms. However, ecological or social sustainability could also be included in the analysis, if these factors are measured in a numerical form. Optimization can further be categorized into linear programming (LP), GP, mixed integer programming (MIP) and heuristic optimization methodologies.

\section{Linear Programming (LP)}

In its simplest form, an LP model includes one objective to be maximized or minimized, with all other objectives expressed as constraints. Economic incomes or amount of biomass are usually factors to be maximized; however, one objective can be a linear combination of several objectives. In LP, the following characteristics of the problem are assumed: linearity of objectives, additivity of values, divisibility of the area treated and certainty of all functions included [42]. Sustainability features are typically included in the form of constraints. Therefore, a loss in short-term profitability can be interpreted as the cost of ensuring sustainability [43]. The amount and structure of loss is dependent on the definition and operationalization of sustainability in the optimization problem.

\section{Goal Programming (GP)}

GP minimizes the deviation between the achievement of the goals and their aspiration levels [44]. In GP, all objectives are expressed as goal constraints, and thereby all objectives are treated similarly, although target values affecting the outcome can be chosen arbitrarily. Because GP is considered to be a special case of LP with an infinite number of potential alternatives, in this study GP is included to optimizing methods. However, when multiple objectives are included, it can also be defined as a MCDA method [41]. Arp and Lavigne [45] demonstrated a GP model including goals on timber, recreation, hunting and wildlife, Gómez et al. [46] proposed a linear fractional GP model of a timber harvest scheduling problem and Bertomeu and Romero [47] presented a GP model for managing forest biodiversity.

\section{Mixed Integer Programming (MIP)}

In cases where some variables are integers, a contiguous MIP can be useful. However, the number of constraints is limited and the problem may be too complex to be solved [37]. The MIP is typically used when the problem includes spatial constraints. It has been used by Walters and Cox [48] for industrial harvest scheduling with sustainable forestry initiative principles, and by Bevers and Hof [49] to optimize 
habitat configuration resulting from forest treatment with respect to wildlife edge effects. In turn, Öhman and Wikström [50] used the MIP to incorporate aspects of habitat fragmentation, and Jiang et al. [51] to design a nature reserve network.

\section{Heuristic Optimization}

The application of heuristic optimization methods provides nearly optimal solutions without completely guaranteeing either the feasibility or optimality of the results. However, heuristic optimization overcomes several limitations of the previously discussed optimization techniques. In contrast to LP, heuristic optimization has no strict requirements for the data because there is no assumption of linearity or divisibility. Additionally, heuristic optimization is more comprehensive and adaptable to different optimization problems. Heuristic optimization problems might include one objective or a linear combination of several objectives or an objective function similar to GP [12]. Heuristic methods have been applied by Kangas et al. [19] for improving the quality of spatial forest planning, whereas Heinonen and Pukkala [52] and Jumppanen et al. [53] utilized them to develop harvest schedule. Pukkala et al. [54], in turn, have used these methods for predicting timber harvests, and Boston and Bettinger [55] have applied heuristics to define the economic impact of green-up constraints. Kurttila et al. [56] employed heuristics in multi-objective forest planning to improve the spatial pattern of the habitats of the flying squirrel (Pteromys volans) and moose (Alces alces), and Pukkala et al. [57] have developed a spatial application of the decomposing technique first proposed by Hoganson and Rose [58].

\section{Cost-Benefit Analysis (CBA) and Monetary Valuation Methods}

CBA is a calculation method for evaluating the profitability of a decision. If the benefits of the decision exceed the costs, the decision is profitable and should be actualized, whereas if the costs exceed the profits, the decision should not be taken. CBA does not require stakeholders' participation, but monetary evaluation methods such as choice experiment (CE) or contingent valuation (CV) are regularly utilized simultaneously to provide data for CBA on the values of non-market products and services. Participation is then passive, but according to Glass [29] such an approach is appropriate if the goal of participation is representing public preferences rather than social learning or conflict resolution. Often results obtained by using CBA or monetary valuation are used as an input to other methods, however these methods can just as well be used as the only method to assist decision-making process.

Despite its simplicity, the CBA can be costly. It is beneficial only when decisions are of a reasonable size; hence, the cost of the CBA should not exceed the benefit gained by using it. The environmental and social consequences are stressed in the same unit as the economic profits. The challenges of the employment of a CBA are connected, for example, to the appraisal of non-renewable natural resources [59] and the selection of 'appropriate' discount rates to reflect the time preferences of the decisionmakers [60], which crucially affect the CBA evaluation results. The CBA has been used to assess carbon storage [61], forest conservation [62], wilderness preservation [63] and value biodiversity [64].

Environmental valuation methods estimate the monetary values of environmental goods or services. In the empirical applications of these methods, the number of alternatives is restricted, and respondents have no power to affect the hypothetical alternatives, which are defined by the compilers of the questionnaire. The respondents are asked their willingness to pay (WTP) for a positive environmental change or willingness to accept (WTA) compenzation for deterioration. WTP can be evaluated by either CV or CE questions. Although monetary valuation can be the only decision-making method, it is often used as an input to other methods (mainly CBA). Monetary valuation has been used, for example, to assess forest certification [65], eco-labeling $[66,67]$, conservation [68-70] and recreational use [71-75], to value biodiversity $[76,77]$, assess recreational uses such as hunting and game management $[78,79]$ evaluate scenic beauty [80] and understand land use planning [81].

When using valuation methods, it must be acknowledged that the actual payment that people are willing to donate might be considerably smaller than the amount they express in enquiries [82, 83]. People might also be worried about possible changes in the prices and state smaller WTP [84]. Additionally, respondents' incomes and places of residence, among others, can affect the amount people are willing to donate $[70,80]$. Moreover, the expressed amount of payment might not entirely capture peoples' relationships with the environment [85]. By contrast, the employment of valuation methods can increase the participation of the general public.

\section{Multi-Criteria Decision Analysis (MCDA)}

The field of MCDA has developed quickly during the past 25 years, with divergent schools of thought emerging [11]. MCDA is based on preference measuring: the assumption that people are able to state whether they prefer option A or B and the strength of their preference [12]. The strengths of MCDA include the capability to deal with qualitative and quantitative data, which might include uncertainties. When letting stakeholders express their goals, build the decision model and negotiate respective criteria before preference measurements and the analysis of alternatives, MCDA can also be regarded more widely as a mixed methods application because active participation and problem structuring is enhanced. In this paper, only discrete MCDA methods were included. On the other hand, GP is often considered to be a continuous MCDA-method. In this paper GP is included to optimization methods.

\section{Multi-Attribute Utility/Value Theory (MAUT/MAVT)}

Multi-attribute utility/value theory (MAUT/MAVT) was one of the first MCDA methods [86] and has several modifications. It transforms diverse criteria (such as costs, risks and stakeholder acceptance) into a single utility or value to enable the comprehensive comparison of decision alternatives. The alternative with the highest utility or value is then selected. MAUT and MAVT are compensatory methods; thus, poor scores in one criterion can be compensated by high scores in other criteria. The difference 
between MAUT and MAVT is that MAVT value functions exclude decision-makers' risk preferences, whereas MAUT utility functions include these [12]. MAUT has been applied to selecting policy and financing instruments for the preservation of the forest [87], whereas MAVT has been used by Ananda and Herath [88] to model stakeholder values in forest planning.

\section{Analytic Hierarchy Process (AHP)}

The AHP [89] is one of the most applied MCDA methods. It emphasizes decision-makers' preferences using pairwise comparisons of criteria and alternatives based on a nine-point preference elicitation scale. The process is straightforward because the comparison of two alternatives is more accessible than choosing the best alternative from several alternatives. However, as the number of comparisons increases, the method requires immense time and effort from decision-makers. This problem can be avoided by statistically modelling the pairwise comparison data [90].

The AHP has been applied to natural resources management [19, 91, 92] and risk assessment [93, 94] as well as using ecological expertise in forest planning [95] and eco-labeling and certificating for forest products [96]. Furthermore, the AHP has been used to choose and prioritise the C\&I of sustainability [97-99], assess the sustainability of forest management plans [100] and analyze the participation of stakeholders [101]. In addition, statistical modelling techniques have been developed that enable the analysis of uncertainties of pairwise comparisons data $[90,102,103]$.

\section{Analytic Network Process (ANP)}

The ANP is an extension of the AHP [104] that focuses on dealing with dependencies among criteria. Wolfslehner et al. [105] compared the AHP and ANP with four different strategic management options with $\mathrm{C} \& \mathrm{I}$, resulting in a different ranking of alternatives. Vacik et al. [106], in turn, evaluated forest management strategies with the ANP and the indicators of SFM, providing a holistic evaluation of different strategies. Also, ANP has been applied to evaluate forest management plans in SFM framework [107]. In general, the number of published applications of the ANP is limited compared to AHP applications.

\section{Outranking Methods}

Outranking methods seek a degree of dominance of one alternative over another and allow the utilization of ordinal and more or less descriptive information [108]. The families of ELECTRE [109] and PROMETHEE [110] are the best known outranking methods. They have been applied to forest management [24] and the participatory natural resource planning process [111].

\section{Stochastic Multi-Criteria Acceptability Analysis (SMAA)}

In addition to the statistical models related to AHP, SMAA [112] is an example of the MCDA methods that enable the analysis of uncertainties. The original SMAA methods performed a weight/space analysis based on additive utility or value function [12]. SMAA has several modifications. For instance, SMAA-2 [113] has been used for stochastic multi-criteria decisions with multiple decision- makers and SMAA-O [114] for treating both ordinal and cardinal criteria. SMAA-O has also been applied to ecosystem management planning $[115,116]$, whereas SMAA-2 has been used in participatory forest planning [117] and dealing with dependent uncertainties in forest planning [22].

\section{Other Methods}

Besides the above-mentioned methods, other less formal techniques, tools and approaches have been used to assist decision-making. In this paper, for the sake of clarity, these are collected together under the heading of other methods. They are sometimes used as the only method to assist the decision-making process or concurrently with other methods. Most of these other methods are used as problem structuring tools. They can also be applied to evaluate the preferences of stakeholders or organise indicators. One shared feature is their capability to enhance participation and be included as components into various DSS.

\section{Soft OR}

Methods discussed above provide few opportunities for stakeholders to modify the decision process other than defining criteria and decision alternatives. As response, Soft OR provides tools for problem structuring and is easily understandable because of its graphical presentations and use of language rather than mathematics [118]. Soft OR includes several methods such as the soft systems methodology (SSM) [119], strategic choice approach (SCA) [120] and strategic options development and analysis (SODA), where the intention is to help individuals consider the nature of the problem through negotiations supported by a facilitator [121].

\section{Cognitive Mapping (CM)}

$\mathrm{CM}$ is an essential part of SODA and supports the structuring of the problem by providing visualization in a form of loops, linkages and possible trade-offs between the concepts. This can enhance understanding of the process, especially if the decision-makers are unfamiliar with numerical methods. CM can be derived from interviews, texts, questionnaires or causal relationship data. CM was first introduced by Axelrod [122], but its applications in sustainable natural resource management are limited, but they have been applied to reveal ideas and thought of the stakeholders. Tikkanen et al. [123] mapped individual forest owners' objectives by CM during interviews. The results differed from those obtained from previous studies conducted with questionnaires. Robson and Kant [124] indentified forest co-management consensus-building criteria with assistance of CM. Also Isaac et al. [125] assessed local knowledge use in agroforestry management with CM.

\section{SWOT and A'WOT}

SWOT (strengths, weaknesses, opportunities and threats) is a well-known and simple method where strengths, weaknesses, opportunities and threats of the problem are revealed. However, linking the SWOT results to the following stages of the decision process is difficult [126]. To improve the usability of SWOT, a hybrid method, A'WOT 
(AHP in SWOT analysis), has been developed [96]. Using AHP within a SWOT framework helps to systematically evaluate the SWOT factors and equate their intensities [126]. A'WOT has been used in the strategic planning of natural resource management at the Finnish Forest and Park Service [126], for forest certification [96] and for the strategic planning of a regional forest research unit [127]. Additionally, SWOT can be included other MCDA methods such as SMART and SMAA.

\section{Interviews}

Interviewing can comprehensively assess the objectives of the stakeholder, with SWOT or CM able to be compiled during an interview. Thematic interviews guide the direction to the discussion using certain themes, and this can help stress essential topics. Because interviewing requires considerable time and effort, the number of the interviews is usually low, which renders qualitative analysis and decision modelling but not statistical analysis. Pykäläinen [128] tested thematic interviews in interactive planning to define the goals of forest owners in numerical form.

\section{Voting}

Voting has for centuries been an important way of expressing decision-making opinions. However, it can neglect the voice of minorities and manipulation by voters is common [117, 129]. Voting has been used in strategic participatory planning [130] to reveal stakeholders' preferences in participatory forest planning [117] and sustainable timber harvesting [131].

\section{CASE STUDY MATERIALS}

To compare methods supporting sustainable natural resources management, a sample of 35 case studies (Table $\mathbf{1}$ ) published in refereed journals were assembled. The case studies included the implementation of sustainability, mostly related to forest management, but also those related to fisheries, marine protection, watercourse regulation and wetlands. The papers were gathered using Google (www.google.com) and the ScienceDirect database (www.sciencedirect.com), with the search keys 'sustainable', 'forestry', 'natural resources' and 'decision support', and with the names of the methods. No geographical or chronological constraints were included. Papers were gathered also from the reference lists of available papers. If several papers assessed certain methods, the papers were selected on the method being used, with as many different methods as possible included in the evaluation. Hybrid case studies were the most difficult to find, and consequently only eight were included. Many of the 35 papers analyzed used the word 'sustainability' but in some cases the sustainability of the process was addressed indirectly; for example: “...information is needed about ecological consequences of alternative plans, such as effects on biodiversity or on different animal and plant species persisting in the area. Information is also required about prices of timber, and costs of forest management options. Finally, information is required about values, opinions and preferences of decisionmakers and other stakeholders" [22].
The focus of some studied papers was on methodological development and those were only illustrative without offering a direct empirical value. Nevertheless, they provided reasoned information on the possibilities of various methods to support the sustainable use of natural resources.

The 35 case studies were divided into four groups with respect to the utilized methods: 1) optimization, 2) CBA and monetary valuation methods, 3) MCDA and 4) hybrid methods (Table 1). Hybrid methods included case studies where two different methods were utilized: MCDA and one of the following: SWOT, CM, voting or interview.

\section{Evaluation Criteria to Analyze the Cases}

The selected 35 cases and the decision support methods related to them were evaluated according to five criteria selected from the recommendations obtained from the previous studies discussed in the introduction:

1. utilization of international or national C\&I;

2. participation of stakeholders and/or experts and the general public;

3. passive and active participation;

4. use of ecological, economic and social indicators; and

5. technical- or problem-orientated nature of problem structuring.

In terms of defining the $\mathrm{C} \& \mathrm{I}$, the case studies were examined to reveal international and national indicator lists. If the decision criteria were defined directly by the authors of the studied papers or the stakeholders related to the studied cases, they were not considered an actual implementation of existing lists of $\mathrm{C} \& \mathrm{I}$.

Information on participants was collected from the case studies. In this paper, participation was divided into two groups: participation of experts/stakeholders and participation of the general public. Participation of the general public is related to obtaining information on opinions, values and preferences [132, 133]. Advantageous participation should include both the general public and experts [134].

Participation was further classified to passive and active participation based on the activity level of the participants. Passive participation includes stating preferences, filling out questionnaires or answering questions compiled by the interviewer. Thus, stakeholders have only a marginal influence over the process. Active participation, on the contrary, allows stakeholders to modify the process. If stakeholders' influence is minimal, the motivation to participate in the process decreases [22]. Active participation of locals could provide reliable knowledge [135], which might not be the case if participation does not permit open discussion and modification of the process.

The variables, indicators and other information used in the case studies were divided into economic, ecological and social factors. Because cultural indicators are difficult to separate from social indicators, they were included to social sustainability. To be genuinely sustainable, all three 
Table 1. The Analyzed 35 Cases Grouped into Optimization, CBA and Monetary Valuation Methods, MCDA and Hybrids

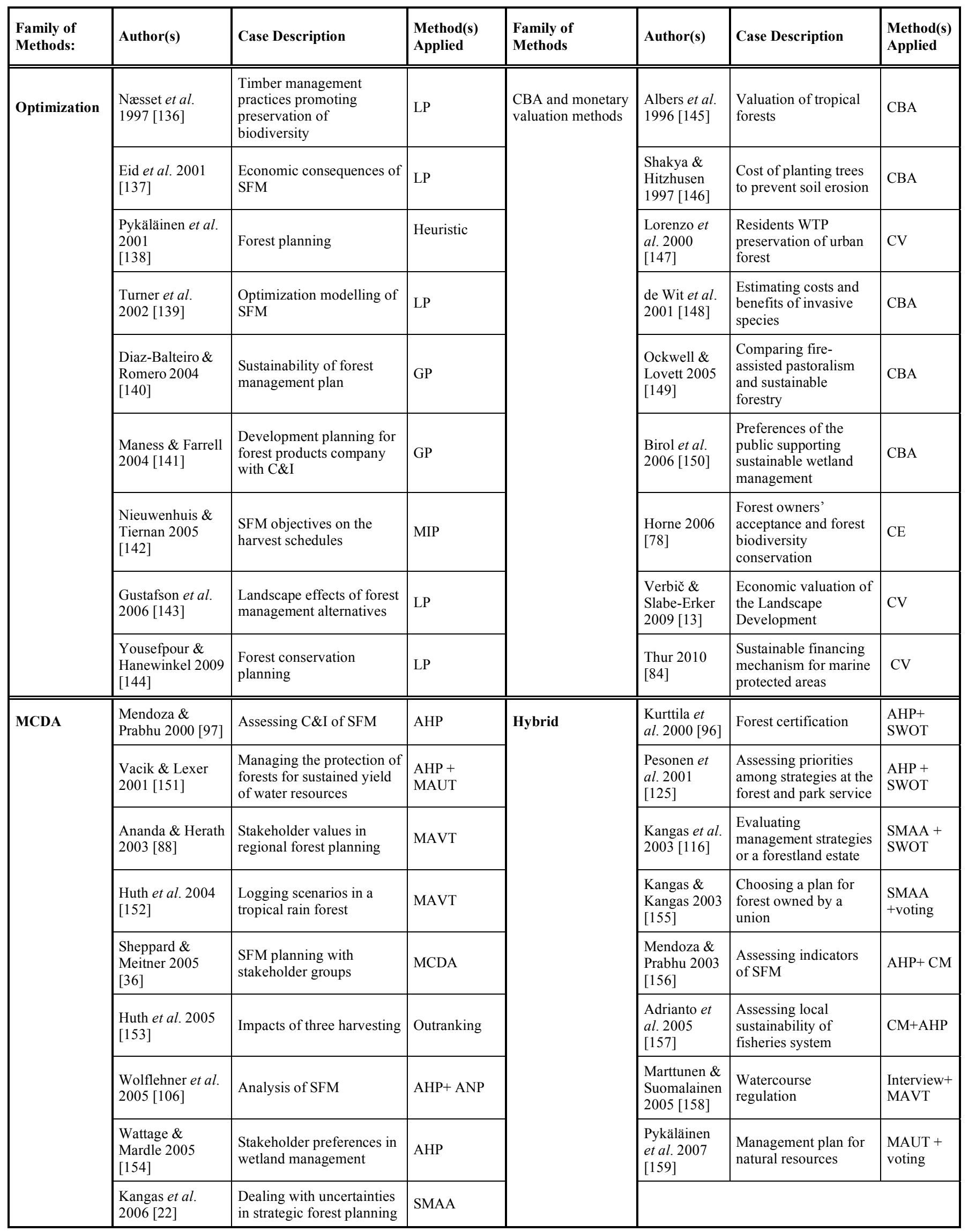


dimensions of sustainability should be observed. Dividing factors strictly into ecological, economic and social dimensions is, however, problematic. For instance, hunting could be classified into any of three dimensions of sustainability: hunting can generate economic profits and game management can additionally increase biodiversity. The social aspects of hunting and game management are dominant; thus, hunting in this paper is included within social sustainability.

The first phase in the decision process is to identify the problem and recognize the relevant factors and stakeholders in regard to the focus area [11]. After the problem structuring process, the choice of a suitable method can take place because different methods fit in different decision processes. However, the facilitator usually has expertise only in certain specific methods, and the method chosen has often been selected beforehand. Therefore, the method utilized in the process might not be the most suitable for the problem at hand. In this study, the paper was considered technically orientated, when the introduction of the studied papers described the advantages and limitations of the methods. In that case, the aim of the paper was to test a certain method that had probably been selected beforehand. By contrast, the paper was considered to be problem-orientated, when the introduction of the paper described the problem and the factors affecting the problem to be solved. In that case, the main focus was on the problem rather than on the methods. Additionally, a time horizon utilized in case studies was observed. In principle, longer time horizons support more sustainable decisions because future consequences are examined.

\section{ANALYSIS OF DIFFERENT DECISION SUPPORT METHODS}

The outcome of the analysis of the case studies is illustrated in Tables 2-6. The observed differences between the methods of supporting the sustainable use of natural resources are discussed next.

C\&I were frequently mentioned, especially in the MCDA papers, but only in few case studies national or international indicators were utilized directly (Table 6). Instead of employing established national or international indicators, the indicators were defined by the authors, experts or stakeholders. Because the C\&I approach to sustainable development is relatively new, the indicators were less abundant in the earlier papers.

The participation of stakeholders was relatively frequent: approximately half the papers included the participation of stakeholders, experts or the general public or all three groups in the evaluations (Table 6). Participation was especially associated with the MCDA and monetary valuation papers (Tables 3-5), whereas participation was rare in optimization methods applications: only one optimization paper included participation in the decision-making process (Table 2). The participants in MCDA and hybrid case studies were mostly experts and stakeholders from various organizations, whereas the participation of general public was rare. By contrast, public participation was frequent in the monetary valuation papers (Table $\mathbf{3}$ ).
The form of public participation was mostly passive including filling questionnaires and preference measurements (Table 3). Experts and stakeholders, on the contrary, more often played an active role in the process (Tables 4 and 5): for instance, experts defined the objectives and indicators. In a few case studies where passive methods were used, stakeholders were reluctant to participate, or the response rate was low $[78,147]$. When the topic was considered important, even passive methods received a high response rate [84].

The three dimensions of sustainability were not represented equally in the case studies (Table 6). Ecological and economic sustainability were considered in almost all case studies, whereas social sustainability was less processed (approximately $60 \%$ of case studies), especially when optimization (Table 2) or CBA and monetary valuation (Table 3) was used. Even when all three dimensions of sustainability were incorporated into the examinations, one or more were given less focus, e.g., social sustainability was evaluated only by recognizing some recreational value [137, 140]. Economic indicators were mainly related to incomes and costs, whereas the ecological indicators utilized included biodiversity, area of old growth forest, key habitats, carbon accumulation and conservation, for example. Social indicators employed in the case studies were, for instance, the visual quality of the landscape, berry and mushroom yield, recreational values and jobs. Additionally, the participation of the general public also indicated social sustainability. In this study, however, participation was not acknowledged as an indicator of social sustainability; it was rather considered a way to approach sustainability.

In most papers, problem structuring was technically orientated (Tables 2-6) in such a way that the purpose of the papers was merely to test or develop the methods selected beforehand. The monetary valuation methods, however, were problem-orientated, with less focus on technical issues. Systematic feedback in the form of feedback questionnaires was rarely collected from participants. However, in some papers [36, 97, 156] participants seemed content with the processes and the methods seemed comprehensively applied.

\section{DISCUSSION AND FURTHER WORK}

The results of the literature review of the 35 case studies showed that the different methods contribute to the dimensions of sustainability in various ways. The participation of stakeholders was uncommon in the optimization and CBA case studies. Stakeholder participation is nevertheless possible with the optimization approaches, for instance when the preferences of the general public are included in the valuations and expert views are used to assess targets and thresholds [141]. The results imply that more attention should be paid to the participation of stakeholders if optimization is to be used in planning the sustainable management of natural resources. General public participation was common in the monetary valuation case studies. However, the role of the general public was mostly passive because they had no power to influence or modify the decision-making process. The preferred role of the general public in the decision-making process should depend on the decisions to be made [29]. In the MCDA and hybrid 
Table 2. Results of the Optimization Case Studies Evaluated with Criteria and Timelines Considered (if Mentioned). ' $X$ ' Denotes a Positive Occurrence of Criteria, whereas an Empty Box Shows that the Criterion was not Observed

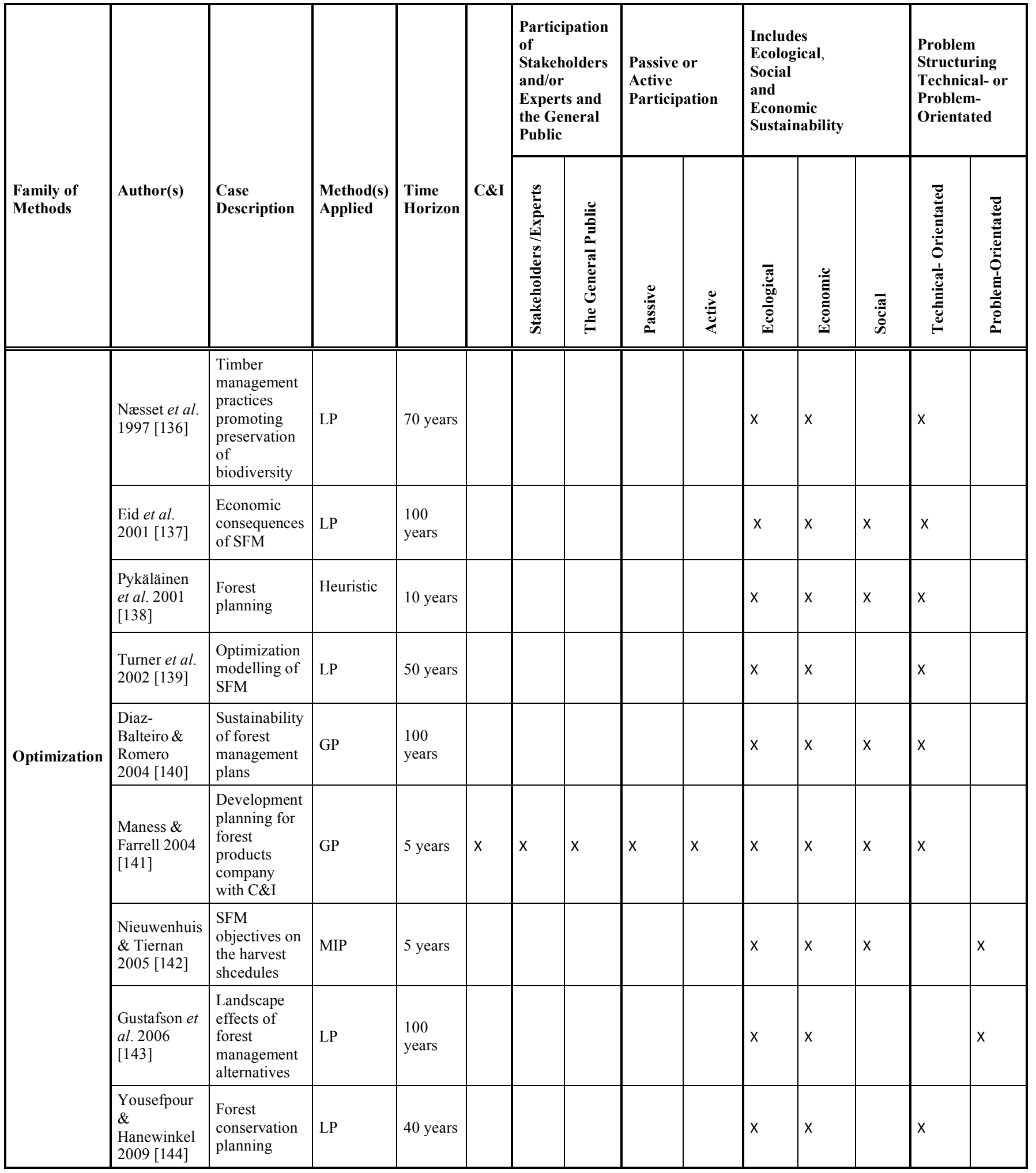

case studies, the involvement of the general public was mostly absent because participants were more often experts with a more active role in the decision-making process. In MCDA papers, a typical task for stakeholders was to select and prioritise the indicators of sustainability. In most case studies, participants took part only in the problem structuring phases, and the authors completed the analysis. Stakeholders with expertise in decision-making could be included in some phases of the analyses, however, for the members of the general public this might not be functional because they 
Table 3. Results of the Monetary Valuation Case Studies Evaluated with Criteria and Timelines Considered (if Mentioned). ' $X$ ' Denotes a Positive Occurrence of Criteria, whereas an Empty Box Shows that the Criterion was not Observed

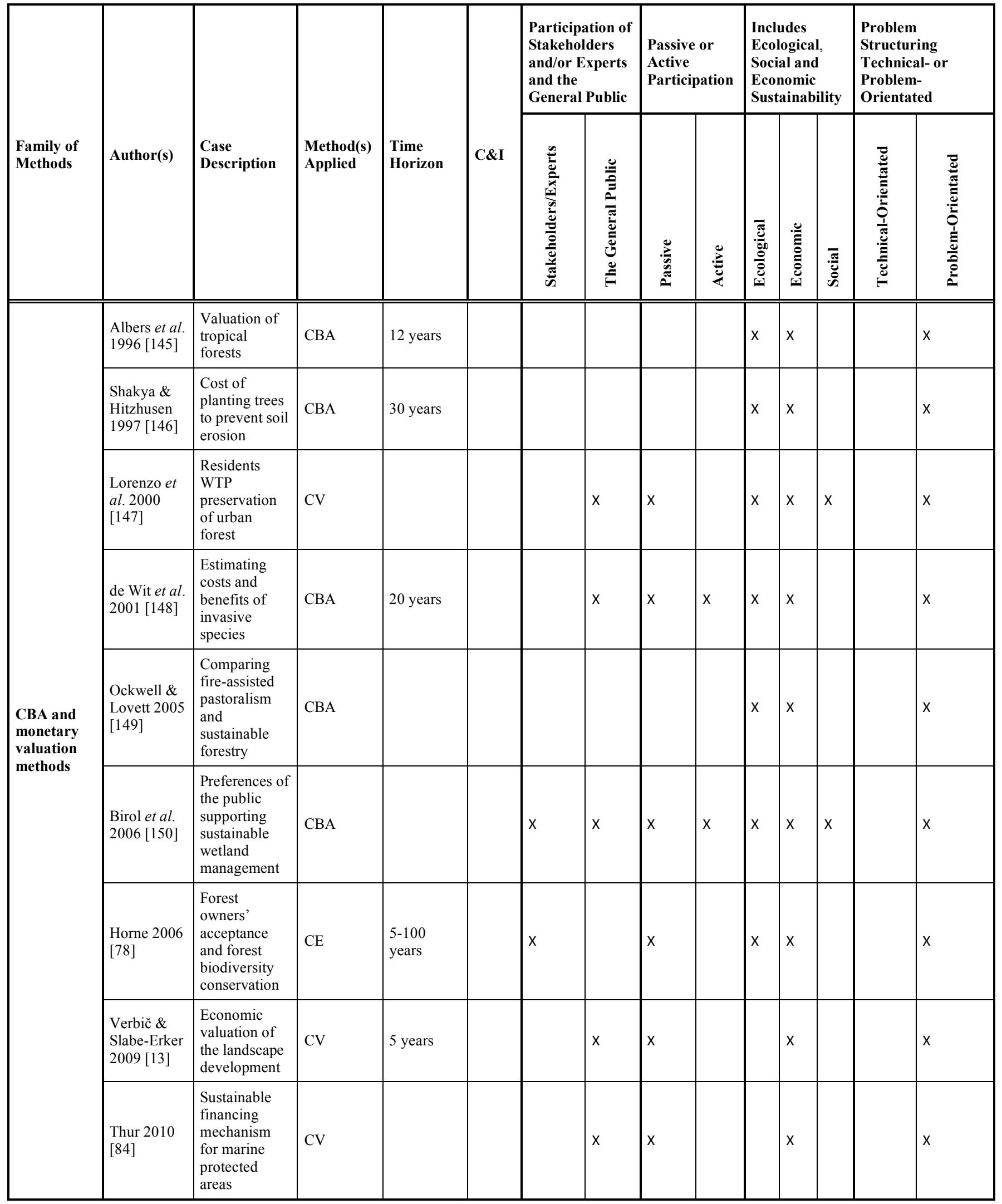


Table 4. Results of the MCDA Case Studies Evaluated with Criteria and Timelines Considered (if Mentioned). ' $X$ ' Denotes a Positive Occurrence of Criteria, whereas an Empty Box Shows that the Criterion was not Observed

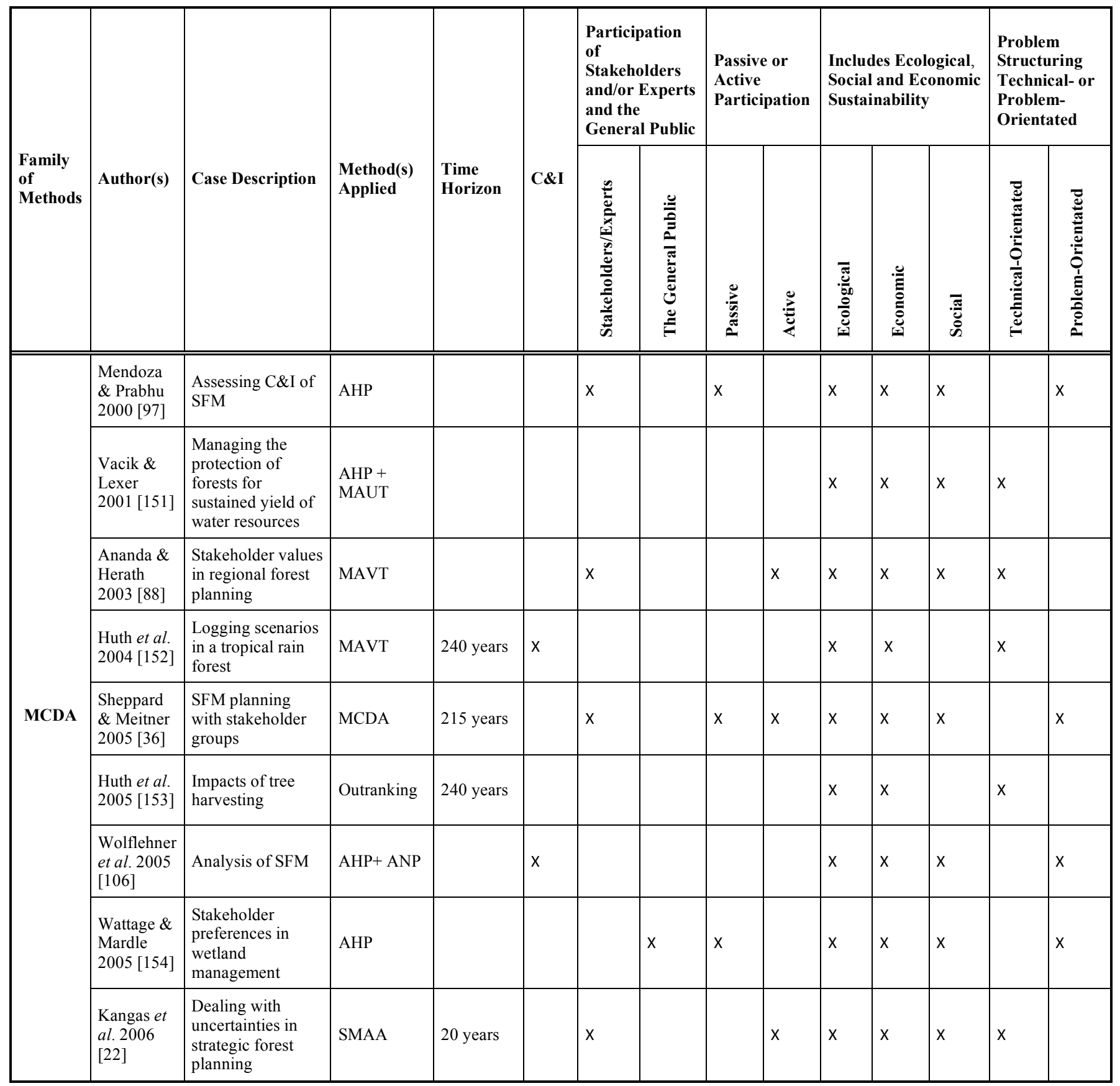

might consider analyses too complicated to interpret. Consequently, it is reasonable to use comprehensible methods when there are members of the general public involved. Also, educating participants should be an essential part of the process if they have little experience on the methods. Nevertheless, including participants from the general public with a more active role in the decision-making process might not always promote sustainability, because their goals, strategies or practices can conflict with the principles of sustainability [134]. It should also be considered how much weight should be given to intuitive thinking by the general public when decisions are made [39].
However, the participation of stakeholders does not necessarily mean that they have actual possibilities to influence the outcomes of the decision-making process. Such outcomes can often be decided beforehand, and in reality participation is used to convince participants [160]. Because the monitoring and evaluation of participatory processes have been neglected, the actual impact of participation on decisions is often unclear [161].

Hybrid methods are thought to improve participation and the problem structuring of the process. Although hybrid methods are in active development in research, there was only a small amount of actual case studies where they had 
Table 5. Results of the Hybrid Case Studies Evaluated with Criteria and Timelines Considered (if Mentioned). When Positive Observation of Criteria is Revealed the $X$ is Inserted. An Empty Box Shows that the Criterion was Not Observed

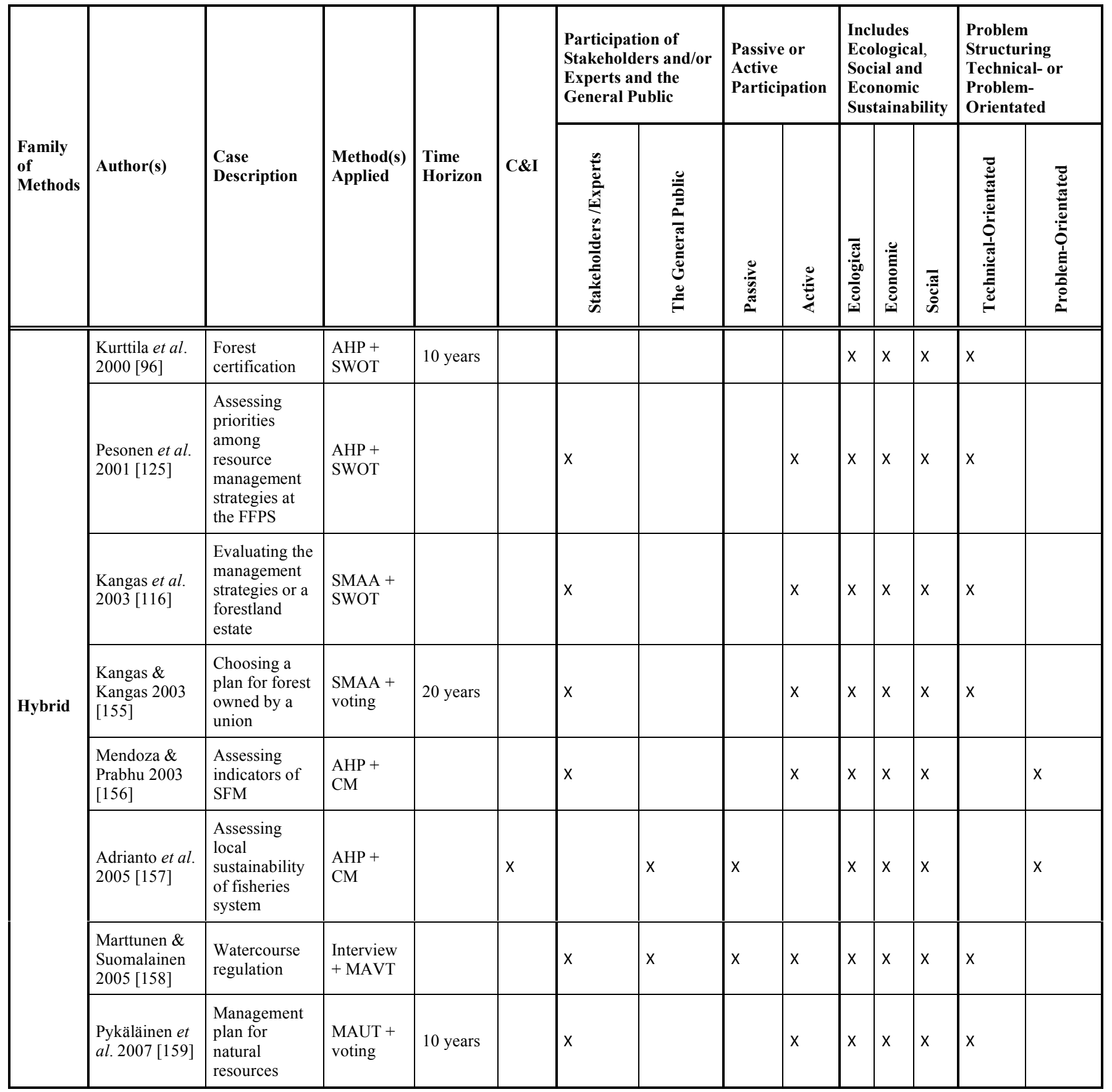

been utilized to support the sustainable use of natural resources. Because only eight hybrid case studies were included in this study, with most using MCDA and qualitative methods, there were some uncertainties comparing hybrids with the other families of methods. Furthermore, hybrid method cases, where monetary valuation or optimization was used, could not be found. In the hybrid case studies, more focus was given to defining the relevant factors and linkages, and thereby the problem structuring phase was given more attention. When a hybrid method was chosen, authors had an idea why one single method would be unsuitable, and consequently the methodological issues were given more attention. In hybrid cases, problem structuring was mostly technical, presumably because of technical challenges (Table 5). In addition, the journal publishing the paper could have influenced the way it was written; thus, papers published in OR journals emphasized the technical issues.

The time horizons in the case studies varied from 5 to 250 years (Tables 2-5), although in almost half the timeline of the research was not mentioned. The studies based on environmental valuation methods had shorter timelines (5-50 years) or the timeline was not considered (Table 3 ) because the purpose of the study was to survey the present state. In the future, valuations of the stakeholders could be different 
Table 6. Summary of the Results: Percentage of the Case Studies from Each Family of Methods Fulfilling the Criteria

\begin{tabular}{|c|c|c|c|c|c|c|c|c|c|c|}
\hline \multirow[t]{2}{*}{ Family of Methods } & \multirow[t]{2}{*}{ C\&I } & \multicolumn{2}{|c|}{$\begin{array}{l}\text { Participation of } \\
\text { Stakeholders and/or } \\
\text { Experts and the } \\
\text { General Public }\end{array}$} & \multicolumn{2}{|c|}{$\begin{array}{l}\text { Passive or Active } \\
\text { Participation }\end{array}$} & \multicolumn{3}{|c|}{$\begin{array}{l}\text { Includes Ecological, Economic and } \\
\text { Social Sustainability }\end{array}$} & \multicolumn{2}{|c|}{$\begin{array}{l}\text { Problem Structuring } \\
\text { Technical- or Problem- } \\
\text { Orientated }\end{array}$} \\
\hline & & $\begin{array}{l}\text { Stake- } \\
\text { Holders } \\
\text { /Experts }\end{array}$ & $\begin{array}{l}\text { The } \\
\text { General } \\
\text { Public }\end{array}$ & Passive & Active & Ecological & Economic & Social & $\begin{array}{l}\text { Technical- } \\
\text { Orientated }\end{array}$ & $\begin{array}{l}\text { Problem- } \\
\text { Orientated }\end{array}$ \\
\hline Optimization & $11 \%$ & $11 \%$ & $11 \%$ & $11 \%$ & $11 \%$ & $100 \%$ & $100 \%$ & $56 \%$ & $78 \%$ & $22 \%$ \\
\hline $\begin{array}{l}\text { CBA and monetary } \\
\text { valuation methods }\end{array}$ & $0 \%$ & $22 \%$ & $56 \%$ & $67 \%$ & $22 \%$ & $78 \%$ & $100 \%$ & $22 \%$ & $0 \%$ & $100 \%$ \\
\hline MCDA & $22 \%$ & $44 \%$ & $11 \%$ & $33 \%$ & $33 \%$ & $100 \%$ & $100 \%$ & $78 \%$ & $56 \%$ & $44 \%$ \\
\hline Hybrid & $13 \%$ & $75 \%$ & $25 \%$ & $25 \%$ & $75 \%$ & $100 \%$ & $100 \%$ & $100 \%$ & $75 \%$ & $25 \%$ \\
\hline
\end{tabular}

or the value of measurement unit could change. Optimization case studies constantly considered the time horizon (Table 2), but the variation was large (5-100 years). The longest time horizons were in MCDA studies (up to 250 years) but the time horizon was often not observed (Table 4). In regard to supporting sustainable development, however, the time perspective of evaluations is a fundamental question. The decisions made at present should not endanger the welfare of future generations, and thereby a longer timeline enhances the sustainability of the decisions. In other words, sustainability within, say, five years could be remarkably different from sustainability within 100 years.

The utilization of national and international indicators was scarce in the case studies (Table 6), because most authors defined the indicators by themselves, or stakeholders and experts were assigned to compile suitable indicators. Based on the results of this study, it could be beneficial to utilise both regional and national indicators concurrently, i.e., multi-scale indicator lists. Regional indicators could be compiled by stakeholders to meet local needs, whereas national indicators could be applied when there is a need to compare regions. For instance, developing and developed countries might have different needs for sustainable development indicators. Indicators utilized in the case studies analyzed in this paper, however, were rather similar to the national and international C\&I. This indicates that indicator sets influenced the selection of suitable decision criteria. For instance, biodiversity is an indicator of ecological sustainability in various lists of indicators [162], and was employed in several case studies, although author(s) did not mention using national or international indicator lists.

The indicator approach to sustainable development has several problems such as a lack of suitable data [9] or difficulties with quantifying indicators [163]. The availability of the data can determine the usage of indicators [139]. The C\&I are foremost used as political tools [9, 107], and thereby their usage in direct decision-making is scarce. The most notable obstacle is an indicator set's failure to meet the challenges and purposes of actual, real-life problems. Because indicator lists have been developed without considering their specific utilization, their application in actual decisions-making might be ambitious [164].
Indicator sets have been compiled since the 1992 Rio Earth Summit and as such the indicator approach is relatively new. In the case studies, the use of indicator sets was concentrated in papers published in the 21 st century. Future indicator approaches with additional modifications could become an established method of assessing the sustainable use of natural resources. Compared with the current situation, these modified indicators should be more problem-oriented, reliable, measurable and available to users. The current verbal targets such as 'preventing biodiversity loss' are often too vague, and this can lead to neglecting targets because of difficulties with monitoring. When applying numerical objectives, by contrast, monitoring can be carried out more comprehensively when reliable data are available. If numerical targets are impossible to compile for some indicators, verbal targets can be applied, but only if there are clear instructions on how they should be acknowledged.

The most problematic dimension of sustainability seems to be social sustainability. In particular, optimization, CBA and monetary valuation case studies failed to evaluate social sustainability (Tables $\mathbf{2}$ and $\mathbf{3}$ ), whereas in the MCDA and hybrid case studies the indicators of social sustainability were included in the examinations (Tables 4 and 5). Indicators of social sustainability are few in number, and can be incomplete, vague, meaningless or difficult to measure in several decision support frameworks [165]. International social indicators are presumably unsuitable for regional decision-making; hence, there is a need for regionally defined social indicators with stakeholder participation. Allowing wider participation with a help of group decision support systems (GDSS) [166] could provide new perspectives to social indicators. It is questionable, whether all relevant social indicators can be directly measured numerically. Thus, the methods utilized to assess the sustainable use of natural resources should deal with both quantitative and qualitative data. In this sense, MCDA methods do not have strict requirements on the data and thereby seem to be promising tools for assessing social sustainability. By contrast, when applying MCDA methods the problem structuring phase is usually not as thorough, and it would be beneficial to use additional methods at that stage of the process. 
Potential tools for problem structuring include CM [156] and SWOT [126, 155], which both have the advantage of being understandable and modifiable. Moreover, in both the participation of stakeholders is active because they can express their opinions and concerns freely. CM can be used to reveal possible linkages between indicators [156] and visualize the problem to stakeholders. A modification of classical CM, fuzzy CM (FCM), enables the modelling of complex relationships, whereas SWOT provides a potential platform for discussing and defining relevant factors and trade-offs. SWOT has been utilized, for instance, in regional forest planning in Finland [126].

Another potential method for problem structuring is soft $\mathrm{OR}$, although its usage in assessing the sustainable use of natural resources is currently limited. The employment of soft OR increases the participation level of stakeholders and provides a detailed definition of the problem including the relevant factors and possible trade-offs [17]. Therefore, applying soft methods in the first phases of the decision process could be beneficial. However, some experts of hard OR think that soft OR focuses on defining the problem, but rarely reaches consensus or provides results. Similarly, soft OR experts can have prejudices against hard OR, believing that it focuses on numbers and quantifying the problem and ignores the actual problem structuring and the people involved. In conclusion, a collaborative transdisciplinary approach is essential to bridge the gap between hard and soft OR.

It is important to use the qualitative preferences of interest groups or local inhabitants with technically sound methods. For example, feedback during and after the planning process is rarely collected [133, 167]. If the feedback is not properly addressed in the creation and selection of the regional strategy, there is a risk that the outcome will be unacceptable in the eyes of different stakeholders. Therefore, developing methods for visualizing and concretizing decisions and their effects on stakeholders and the public is crucial. Generally, decision-makers prefer making decisions based on their own intuition or experience rather than utilizing obscure models and methods [153]. No matter which method is being used, the decision process will never reach absolute objectivity, because even the selection of the method - or initiating a decision process in the first place - is a subjective decision. Additionally, decisionmakers' preferences will influence the selection of data, methods, objectives and stakeholders. Consequently, none of the methods discussed in this paper can be considered objective or equitable.

\section{CONCLUSIONS}

The main focus in this paper was decision-making in forestry and other natural resources, but the findings can be helpful both in a theoretical perspective (e.g., theoretical development of the methods) and practical decision-making. The hybrid decision support methodologies and approaches can be applied in a variety of decision-making situations, and could benefit both the developers and facilitators of DSS as well as decision-makers themselves.

The findings of this paper indicate that the ideal decision support process to promote the sustainable use of natural resources has some special features. First, the methods applied in the process should include economic, ecological and social dimensions. However, because data on the indicators of sustainability can be incomplete, subjective or in numerical or verbal forms, there should be no restrictions on the form of the data used. The ability to apply divergent data poses challenges for the applied methods.

Second, because participation has become an essential part of sustainable development, the methods employed should allow for the participation of various stakeholders. In addition, the methods should be comprehensible, because the stakeholders might have little or no education on the technical details of the methods. Because the available time is limited, the method should also be applicable in a reasonable time and with moderate effort. Additionally, the applied methods should allow the stakeholders to modify the decision-making process, because passive participation, with no actual power to influence the process, can cause distrust and frustration among the participating stakeholders.

Third, during the problem structuring phase all relevant factors from the final decision-making perspective should be addressed and included in the subsequent phases of the process. Nevertheless, revealing the relevant factors and recognizing the trade-offs and conflicts is inadequate because, in most cases, the purpose of the process is to reach conclusions. Consequently, the methods should also provide well-designed tools for evaluating the alternatives and enhancing the agreement on the final outcome among stakeholders.

Fourth, no single method can face the demands of an ideal decision support process, and thereby the utilization of at least two methods might be required. Hybrid methods are potential tools for providing solutions to the participation of stakeholders, data quality, problem structuring and the systematic evaluation of alternatives. Qualitative methods (e.g., CM or SWOT) can provide stakeholders efficient and convenient support in the problem structuring phase, whereas quantitative methods (e.g., MCDA or the various optimization techniques) help them evaluate the different decision alternatives. When deciding on the sustainable use of natural resources, hybrid approaches can provide much needed structure and support for the process.

\section{ACKNOWLEDGEMENTS}

This study was supported by the Academy of Finland (decision number 127681). We would like to thank Dr Leena A. Leskinen for valuable comments during the writing process, and Dr Katja Lähtinen for comments and improvement suggestions on the final manuscript. We also appreciate the comments given by three anonymous referees.

\section{REFERENCES}

[1] United Nations. Agenda 21, Rio declaration, forest principles: drafts. United Nations Conference on Environment and Development in Rio de Janeiro. New York 1992.

[2] Vierikko K, Vehkamäki S, Niemelä J, Pellikka J, Lindén $H$. Meeting the ecological, social and economic needs of sustainable forest management at a regional scale. Scand J Forest Res 2008; 23: 431-44. 
[3] Sinclair AJ, Smith DL. The model forest program in Canada: building consensus on sustainable forest management? Soc Nat Res 1999; 12: 121-38.

[4] Mendoza GA, Prabhu R. Participatory modeling and analysis for sustainable forest management: overview of soft system dynamics models and applications. Foreign Policy Econ 2006; 9: 179-96.

[5] Raitio K. "You can't please everyone" - conflict management practices, frames and institutions in Finnish State forests. Joensuun yliopiston yhteiskuntatieteellisiä julkaisuja nro 86. Doctoral thesis, University of Joensuu, Finland 2008.

[6] Bruntland G, Ed. Our common future: the World Commission on Environment and Development. Oxford: University Press 1987.

[7] Schlaepfer R, Elliot C. Ecological and landscape considerations in forest management: the end of forestry? In: Gadow K, Pukkala T, Tomé M, Eds. Sustainable forest management. Netherlands: Kluwer Academic Publishers 2000; pp. 1-67.

[8] Varma VK, Ferguson I, Wild I. Decision support system for the sustainable forest management. Ecol Manage 2000; 128: 49-55.

[9] Rosenström U. Sustainable development indicators: Much wanted, less used? Helsinki: Edita Prima Ltd 2009.

[10] Martins H, Borges JG. Addressing collaborative planning methods and tools in forest management. For Ecol Manage 2007; 248: 10718.

[11] Belton V, Stewart TJ. Multiple criteria decision analysis: an integrated approach. Massachusetts: Kluwer Academic Publishers 2002 .

[12] Kangas A, Kangas J, Kurttila M. Decision support for forest management. USA: Springer 2008.

[13] Verbič M, Slabe-Erker R. An econometric analysis of willingnessto-pay for sustainable development: a case study of the Volcji Potok landscape area. Ecol Econ 2009; 68: 1316-28.

[14] Lange GM. Manual for environmental and economic accounts for forestry: a tool for cross-sectoral policy analysis. FAO Forestry Department. Working Paper 2004. ftp://ftp.fao.org/docrep/fao/007/ j1972e/j1972e00 [cited 16 March 2009].

[15] Rosenhead J. Rational analysis of a problematic world. John Wiley Sons: New York 1989.

[16] Stirling J. Analysis, participation and power: justification and closure in participatory multi-criteria analysis. Land Use Policy 2006; 23: 95-107.

[17] Hjortsø CN. Enhancing public participation in natural resource management using Soft OR--an application of strategic option development and analysis in tactical forest planning. Eur $\mathrm{J}$ Oper Res 2004; 152: 667-83.

[18] Mendoza GA, Martins H. Multi-criteria decision analysis in natural resource management: a critical review of methods and new modeling paradigms. For Ecol Manage 2006; 230: 1-22.

[19] Kangas J, Store R, Leskinen P, Mehtatalo L. Improving the quality of landscape ecological forest planning by utilizing advanced decision support tools. For Ecol Manage 2000; 132:157-71.

[20] Nordström E-M, Romero C, Eriksson, LO, Öhman K. Aggregation of preferences in participatory forest planning with multiple criteria: an application to the urban forest in Lycksele, Sweden. Can J For Res 2009; 39: 1979-92.

[21] Petkov D, Petkova O, Andrew T, Nepal T. Mixing multiple criteria decision making with soft systems thinking techniques for decision support in complex situations. Decision Support Syst 2007; 43: 1615-29.

[22] Kangas A, Kangas J, Lahdelma R, Salminen. Using SMAA-2 method with dependent uncertainties for strategic forest planning. For Policy Econ 2006; 9: 113-25.

[23] Kajanus M, Kangas J, Kurttila $M$. The use of value focused thinking and the A'WOT hybrid method in tourism management. Tourism Manage 2004; 25: 499-506.

[24] Kangas J, Kangas A. Multiple criteria decision support in forest management-the approach, methods applied, and experiences gained. For Ecol Manage 2005; 207: 33-143

[25] Ananda J, Herath G. The use of analytic hierarchy process to incorporate stakeholder preferences into regional forest planning. Foreign Policy Econ 2003; 5: 13-26.

[26] Grimble R, Chan MK. Stakeholder analysis for natural resource management in developing countries: some practical guidelines for making management more participatory and effective. Nat Resour Forum 1995; 19: 113-24.
[27] Harrison SR, Qureshi ME. Choice of stakeholder groups and members in multi-criteria decision models. Nat Resour Forum 2000; 24: 11-9.

[28] Arnstein S. A ladder of citizen participation. J Am Inst Plann 1969; 35: 216-24.

[29] Glass JJ. Citizen participation in planning: the relationship between objectives and techniques. J Am Plann Assoc 1979; 45: 180-89.

[30] Webler T, Tuler S, Krueger R. What is a good public participation process? Five perspectives from the public. Environ Manage 2001; 27: 435-50.

[31] Kangas A, Saarinen N, Saarikoski H, Leskinen LA, Hujala T, Tikkanen J. Stakeholder perspectives about proper participation for Regional Forest Programmes in Finland. Foreign Policy Econ 2010; 12: 213-22.

[32] Gamper CD, Turcanu C. On the governmental use of multi-criteria analysis. Ecol Econ 2007; 62: 298-307.

[33] Gregory R. Incorporating value trade-offs into community based environmental risk decisions. Environ Value 2002; 11: 461-88.

[34] Hajkowicz S. A comparison of multiple criteria analysis and unaided approaches to environmental decision making. Environ Sci Pol 2007; 10: 177-4.

[35] Sheppard S, Achiam CM. Public participation in forest decision making. Encycl Fort Sci 2004; pp1173-82.

[36] Sheppard S, Meitner M. Using multi-criteria analysis and visualization for sustainable forest management planning with stakeholder groups. For Ecol Manage 2005; 207: 171-87.

[37] Baskent EZ, Keles S. Spatial forest planning: a review. Ecol Model 2005; 188: 145-73.

[38] Hanley N. Cost-benefit analysis and environmental policymaking. Environ Plann C Gov Policy 2001; 19: 103-18.

[39] Price C. Twenty-five years of forestry cost-benefit analysis in Britain. Forestry 1997; 70: 71-89.

[40] Diaz-Balteiro L, Romero C. Making forestry decisions with multiple criteria: a review and an assessment. For Ecol Manage 2008; 255: 3222-41.

[41] Malczewski J. GIS and multicriteria decision analysis. New York: Wiley 1999.

[42] Dantzig GP. Linear programming and extensions. Princeton: Princeton University Press 1959

[43] Eid T, Hoen HF, Økseter P. Timber production possibilities of the Norwegian forest area and measures for a sustainable forestry. Forest Pol Econ 2002; 4: 187-200.

[44] Romero C. Handbook of critical issues in goal programming. Pergamon Press 1991.

[45] Arp PA, Lavigne DR. Planning with goal programming: a case study for multiple-use of forested land. For Chron 1982; 58: 22532 .

[46] Gómez T, Hernandez M, Leon MA, Caballero R. A forest planning problem solved via a linear fractional goal programming model For Ecol Manage 2006; 227: 79- 88.

[47] Bertomeu M, Romero C. Managing forest biodiversity: a zero-one goal programming approach. Agric Syst 2001; 68: 197-213.

[48] Walters KR, Cox ES. An empirical evaluation of spatial restrictions in industrial harvest scheduling: the SFI planning problem. South J Appl For 2001; 25: 60-8.

[49] Bevers M, Hof J. Spatially optimizing on wildlife habitat edge effects in forest management linear and mixed-integer programs For Sci 1999; 45: 249-58.

[50] Öhman K, Wikström P. Incorporating aspects of habitat fragmentation into long-term forest planning using mixed integer programming. For Ecol Manage 2008; 255: 440-6.

[51] Jiang Y, Swallow SK, Paton PWC. Designing a spatially-explicit nature reserve network based on ecological functions: an integer programming approach. Biol Conserv 2007; 140: 236-49.

[52] Heinonen T, Pukkala T. A comparison of one- and two compartment neighborhoods in heuristic search with spatial forest management goals. Silva Fenn 2004; 38: 319-32.

[53] Jumppanen J, Kurttila M, Pukkala T, Uuttera J. Spatial harvest scheduling approach for areas involving multiple ownership. For Ecol Manage 2003; 5: 27-38.

[54] Pukkala T, Ketonen T, Pykäläinen J. Predicting timber harvests from private forests - a utility maximisation approach. For Pol Econ 2003; 5: 285-96.

[55] Boston K, Bettinger P. The economic impact of green-up constraints in the southeastern United States. For Ecol Manage 2001; 145: 191-202. 
[56] Kurttila M, Pukkala T, Loikkanen J. The performance of alternative spatial objective types in forest planning calculations: a case study for Siberian flying squirrel and moose. For Ecol Manage 2002; 166: 245-60.

[57] Pukkala T, Heinonen T, Kurttila M. An application of the reduced cost approach to spatial forest planning. For Sci 2009; 55: 13-22.

[58] Hoganson HM, Rose DW. A simulation approach for optimal timber management scheduling. For Sci 1984; 30: 220-38.

[59] Price C. The theory and application of forest economics. The University of Wales Bangor Basil Blackwell Ltd 1989.

[60] Hansjürgens B. Economic valuation through cost-benefit analysispossibilities and limitations. Toxicology 2004; 205: 241-52.

[61] Lohmann L. Toward a different debate in environmental accounting: the cases of carbon and cost-benefit. Acc Org Soc 2009; 34: 499-534.

[62] Kniivilä M, Ovaskainen C, Saastamoinen O. Costs and benefits of forest conservation: regional and local comparisons in Eastern Finland. J For Econ 2002; 8: 131-50.

[63] Porter RC. The new approach to wilderness preservation through benefit-cost analysis. J Environ Econ Manage 1982; 9: 63-80.

[64] Bräuer I. Money as an indicator: to make use of economic evaluation for biodiversity conservation. Agric Ecos Environ 2003; 98: 483-91.

[65] Aguilar FX, Vlosky RP. Consumer willingness to pay price premiums for environmentally certified wood products in the U.S. For Pol Econ 2007; 9: 1100-12.

[66] Veisten K. Willingness to pay for eco-labelled wood furniture: choice-based conjoint analysis versus open-ended contingent valuation. J For Econ 2007; 13: 29-48.

[67] Hicks RL, Schnier KE. Eco-labeling and dolphin avoidance: a dynamic model of tuna fishing in the Eastern Tropical Pacific. J Environ Econ Manage 2008; 56: 103-16.

[68] Hoyos D, Mariel P, Fernandez-Macho J. The influence of cultural identity on the WTP to protect natural resources: some empirical evidence. Ecol Econ 2009; 68: 8-9.

[69] Cho SH, Newman DH, Bowker JM. Measuring rural homeowners' willingness to pay for land conservation easements. For Pol Econ 2005; 7: 757-70.

[70] Lehtonen E, Kuuluvainen J, Pouta E, Rekola M, Li CZ. Nonmarket benefits of forest conservation in southern Finland. Environ Sci Policy 2003; 6: 195-204.

[71] Tyrväinen L. Economic valuation of urban forest benefits in Finland. J Environ Manage 1998; 62; 75-92.

[72] Tyrväinen L, Väänänen $H$. The economic value of urban amenities: an application of the contingent valuation method. Landscape Urban Plann 1998; 43: 105-18.

[73] Richer JR, Christensen NA. Appropriate fees for wilderness day use: pricing decisions for recreation on public land. J Leisure Res 1999; 31: 269-80

[74] Tyrväinen L, Miettinen A. Property prices and urban forest amenities. J Environ Econ Manage 2000; 39: 205-23.

[75] Huhtala A, Pouta E. User fees, equity and the benefits of public outdoor recreation services. J For Econ 2008; 14: 117-32.

[76] Meyerhoff J, Liebe U, Hartje V. Benefits of biodiversity enhancement of nature-oriented silviculture: evidence from two choice experiments in Germany. J For Econ 2009; 15: 37-58.

[77] Christie M, Hanley N, Warren J, Murphy K, Wright R, Hyde T. Valuing the diversity of biodiversity. Ecol Econ 2006; 58: 304-17.

[78] Horne P. Forest owners' acceptance of incentive based policy instruments in forest biodiversity conservation - a choice experiment based approach. Silva Fenn 2006; 40; 169-78.

[79] Bullock GH, Elston DA, Chalmers NA. An application of economic choice experiments to a traditional land use-deer hunting and landscape change in the Scottish Highlands. J Environ Manage 1998; 52: 335-51.

[80] Biénabe E, Hearne RR. Public preferences for biodiversity conservation and scenic beauty within a framework of environmental services payments. For Pol Econ 2006: 9: 335-48.

[81] Rambonilaza M, Dachary-Bernard J. Land-use plan public preferences: what can we learn from choice experiment method? Landscape Urban Plan 2007; 83: 318-26.

[82] Foster V, Bateman IJ, Harley D. In: Acutt M, Mason P, Eds. Environmental valuation, economic policy and sustainability recent advances in environmental economics. Cheltenham, Edward Elgar pp. $1998 ; 35-50$
[83] Veisten K, Navrud S. Contingent valuation and actual payment for voluntarily provided passive-use values: Assessing the effect of an induced truth-telling mechanism and elicitation format. Appl Econ 2006; 38: 735-56.

[84] Thur SM. User fees as sustainable financing mechanisms for marine protected areas: an application to the Bonaire National Marine Park. Marine Policy 2010; 34: 63-9.

[85] Sagoff M. The economy of the Earth. Cambridge: Cambridge University Press 1988

[86] Keeney RL, Raiffa H. Decisions with multiple objectives. USA: John Wiley \& Sons 1976.

[87] Hayashida T, Nishizaki I, Ueda Y. Multiattribute utility analysis for policy selection and financing for the preservation of the forest. Eur J Oper Res 2010; 200: 833-43.

[88] Ananda J, Herath G. Incorporating stakeholder values into regional forest planning: a value function approach. Ecol Econ 2003; 45: 75-90.

[89] Saaty TL. A scaling method for priorities in hierarchical structures. J Math Psychol 1977; 15: 234-81.

[90] Alho JM, Kolehmainen O, Leskinen P. In: Schmoldt DL, Kangas J, Mendoza GA, Pesonen M, Eds. The analytic hierarchy process in natural resource and environmental decision making. Dortrecht: Kluwer Academic Publishers 2001; pp. 235-51.

[91] Mendoza GA, Sprouse W. Forest planning and decision making under fuzzy environments: an overview and analysis. For Sci 1989; 35: 481-502.

[92] Zadnik-Stirn L. Integrating the fuzzy analytic hierarchy process with dynamic programming approach for determining the optimal forest management decisions. Ecol Model 2006; 194: 296-305.

[93] Kangas J. A multi-attribute preference model for evaluating the reforestation chain alternative of a forest stand. For Ecol Manage 1993; 59: 271-88.

[94] Pukkala T, Kangas, J. A method for integrating risk and attitude toward risk into forest planning. For Sci 1996; 42: 198- 205.

[95] Kangas J, Leskinen P. Modelling ecological expertise for forest planning calculations-rationale examples, and pitfalls. J Environ Manage 2005; 76: 125-33.

[96] Kurttila M, Pesonen M, Kangas J, Kajanus M. Utilizing the analytic hierarchy process AHP in SWOT analysis a hybrid method and its application to a forest-certification case. For Policy Econ 2000; 1: 41-52.

[97] Mendoza GA, Prabhu R. Multiple criteria decision making approaches to assessing forest sustainability using criteria and indicators: a case study. For Ecol Manage 2000; 131: 107-26.

[98] Mendoza GA, Prabhu R. Prioritizing criteria and indicators for sustainable forest management. a case study on participatory decision making. In: Schmoldt DL, Kangas J, Guillermo AM, Pesonen M. Eds. The analytic hierarchy process in natural resource and environmental decision making. Netherlands, Kluwer Academy Publishers 2002; pp. 115-29.

[99] Gomontean B, Gajaseni J, Edwards-Jones C, Gajaseni N. The development of appropriate ecological criteria and indicators for community forest conservation using participatory methods: A case study in northeastern Thailand. Ecol Indic 2008; 8: 614-24.

[100] Mendoza GA, Dalton WJ. Multi-stakeholder assessment of forest sustainability: multi-criteria analysis and the case of the Ontario forest assessment system. For Chron 2005; 81: 222-8.

[101] Mau-Crimmins T, de Steiguer JE, Dennis D. AHP as a means for improving public participation: a pre-post experiment with university students. For Policy Econ 2005; 7: 501-14.

[102] Leskinen P. Statistical methods for measuring preferences. D.Sc. thesis. University of Joensuu, Publications in Social Sciences 2001; p. 48.

[103] Leskinen P, Viitanen J, Kangas A, Kangas J. Alternatives to incorporate uncertainty and risk attitude in multicriteria evaluation of forest plans. For Sci 2006; 52: 304-12.

[104] Saaty TL. Theory and applications of the analytic network process: decision making with benefits, opportunities, costs, and risks. Pittsburgh: RWS Publications 2005.

[105] Wolfslehner B, Vacik H, Lexer MJ. Application of the analytic network process in multi-criteria analysis of sustainable forest management. For Ecol Manage 2005; 207: 157-70.

[106] Vacik H, Wolfslehner B, Seidl R, Lexer MJ. In: Reynolds KM, Thomson AJ, Köhl M, Shannon MA, Ray D, Rennolls K, Eds Sustainable forestry: from monitoring and modelling to knowledge 
management and policy science. Cambridge, CAB International 2007; pp 393-412.

[107] Wolfslehner B, Vacik H. Evaluating sustainable forest management strategies with the analytic network process in a pressure-stateresponse framework. J Environ Manage 2008; 88: 1-10.

[108] Rogers M, Bruen M. A new system for weighting environmental criteria for use within ELECTRE III. Eur J Oper Res 1998; 107: 552-63.

[109] Roy B. The outranking approach and the foundations of Electre methods. Theory Dec 1991; 31: 49-73.

[110] Brans JP, Vincke P. A preference ranking organization method. Manage Sci 1985; 31: 647-56.

[111] Kangas J, Kangas A, Leskinen P, Pykäläinen J. MCDM methods in strategic planning of forestry on state-owned lands in Finland: applications and experiences. J Multi-Crit Decis Anal 2001; 10: 257- 71 .

[112] Lahdelma R, Hokkanen J, Salminen P. SMAA- Stochastic multicriteria acceptability analysis for group decision making. Oper Res 1998: 137-43

[113] Lahdelma R, Salminen P. SMAA-2: Stochastic multicriteria acceptability analysis for group decision making. Eur J Oper Res 2001; 49: 444-54.

[114] Lahdelma R, Miettinen K, Salminen P. Ordinal criteria in stochastic multicriteria acceptability analysis (SMAA). Eur J Oper Res 2003; 147: 117-27.

[115] Kangas J, Kangas A. In: Pukkala T, Eds. Multi-objective forest planning. Dordrecht: Kluwer Academic Publishers: The Netherlands 2002; pp 37-70.

[116] Kangas J, Kurttila M, Kajanus M, Kangas A. Evaluating the management strategies of a forestland estate- the S-O-S approach. J Environ Manage 2003; 69: 349-58.

[117] Vainikainen N, Kangas A, Kangas J. Empirical study on voting power in participatory forest planning. J Environ Manage 2008; 88: 173-80.

[118] Rosenhead J, Mingers J. A new paradigm of analysis. In: Rosenhead J, Mingers J, Eds. Rational analysis for a problematic world: problem structuring methods for complexity, uncertainty and conflict. John Wiley \& Sons: Chichester UK 2001; p 384.

[119] Checkland P. Systems thinking, systems practice. John Wiley \& Sons: Chichester 1981.

[120] Friend J, Hickling A. Planning under pressure: the strategic choice approach. Pergamon, Oxford 1987.

[121] Eden C. Using cognitive mapping for strategic options development and analysis (SODA). In: Rosenhead J, Ed. Rational analysis for a problematic world. Wiley, Chichester 1989.

[122] Axelrod RM. Structure of decisions: the cognitive map of political elites. Princeton University Press, Princeton: New Jersey 1976.

[123] Tikkanen J, Isokääntä T, Pykäläinen J, Leskinen P. Applying cognitive mapping approach to explore the objective-structure of forest owners in a Northern Finnish case area. For Policy Econ 2006; 9: 139-52.

[124] Robson M, Kant S. The development of government agency and stakeholder cooperation: A comparative study of two Local Citizens Committees' (LCCs) participation in forest management in Ontario, Canada. For Pol Econ 2007; 9: 1113-33.

[125] Isaac ME, Dawoe E, Sieciechowicz K. Assessing Local Knowledge Use in Agroforestry Management with Cognitive Maps. Environ Manage 2009; 43:1321-29.

[126] Pesonen M, Kurttila M, Kangas J, Kajanus M, Heinonen P. Assessing the priorities using A'WOT among resource management strategies at the Finnish Forest and Park Service. For Sci $2001 ; 47$; 534-41.

[127] Leskinen LA, Leskinen P, Kurttila M, Kangas J, Kajanus M. Adapting modern strategic decision support tools in the participatory strategy process-a case study of a forest research station. For Policy Econ 2006; 8: 267-78.

[128] Pykäläinen J. Defining forest owner's forest-management goals by means of thematic interview in interactive forest planning. Silva Fenn 2000; 34: 47-59.

[129] Kangas A, Laukkanen S, Kangas J. Social choice theory and its applications in sustainable forest management-a review. For Policy Econ 2006; 9: 77-92.

[130] Hiltunen V, Kangas J, Pykäläinen J. Voting methods in strategic forest planning — experiences from Metsähallitus. For Policy Econ 2008; 10: 117-27.
[131] Laukkanen S, Palander T, Kangas J. Applying voting theory in participatory decision support for sustainable timber harvesting. Can J For Res 2004; 34: 1511-24.

[132] Leskinen L. Purposes and challenges of public participation in regional and local forestry in Finland. For Policy Econ 2004; 6: 605-18.

[133] Hytönen L, Leskinen P, Store R. A spatial approach to participatory planning in forestry decision-making. Scand J Forest Res 2002; 17: 62-71.

[134] Reed SM, Fraser EDG, Dougill AJ. An adaptive learning process for developing and applying sustainability indicators with local communities. Ecol Econ 2006; 59: 406-15.

[135] Reed MS, Dougill AJ, Baker TR. Participatory indicator development: what can ecologists and local communities learn from each other? Ecol Appl 2008; 18: 1253-69.

[136] Næsset E, Gobakken T, Hoen HF. Economic analysis of timber management practices promoting preservation of biological diversity. Scand J For Res 1997; 20: 264-72.

[137] Eid T, Hoen HF, Økseter P. Economic consequences of sustainable forest management regimes at non-industrial forest owner level in Norway. For Policy Econ 2001; 2: 213-28.

[138] Pykäläinen J, Pukkala T, Kangas J. Alternative priority models for forest planning on the landscape level involving multiple ownership. For Policy Econ 2001; 2: 293-306.

[139] Turner BJ, Chikumbo O, Davey SM. Optimization modelling of sustainable forest management at the regional level: an Australian example. Ecol Model 2002; 153: 157-79.

[140] Diaz-Balteiro L, Romero C. Sustainability of forest management plans: a discrete goal programming approach. J Environ Manage 2004; 71: 351-9.

[141] Maness T, Farrell T. A scenario evaluation model for sustainable forest management using criteria and indicators. Can J For Res 2004; 34: 2004-17

[142] Nieuwenhuis M, Tiernan D. The impact of the introduction of sustainable forest management objectives on the optimization of PC-based forest-level harvest schedules. For Policy Econ 2005; 7: 689-701.

[143] Gustafson EJ, Roberts JL, Leefers LA. Linking linear programming and spatial simulation models to predict landscape effects of forest management alternatives. J Environ Manage 2006; 81: 339-50.

[144] Yousefpour R, Hanewinkel M. Modelling of forest conversion planning with an adaptive simulation-optimization approach and simultaneous consideration of the values of timber, carbon and biodiversity. Ecol Econ 2009; 68: 1711-22.

[145] Albers HJ, Fisher AC, Hanemann WM. Valuation and management of tropical forests. Environ Resour Econ 1996; 8: 39-61.

[146] Shakya BS, Hitzhusen FJ. A benefit-cost analysis of the conservation reserve program in Ohio. Are trees part of a sustainable development in Midwest? J Reg Anal Pol 1997: 27; 1330 .

[147] Lorenzo AB, Catalino A. Blanche AC, Yadong Y, Guidry MM. Assessing residents' willingness to pay to preserve the community urban forest: a small-city case study. J Arboric 2000; 26; 318-25.

[148] de Wit MP, Crookes DJ, van Wilgen BW. Conflicts of interest in environmental management: estimating the costs and benefits of a tree invasion. Biol Invas 2001; 3: 167-78.

[149] Ockwell D, Lovett JC. Fire assisted pastoralism vs. sustainable forestry - the implications of missing markets for carbon in determining optimal land use in the wet-dry tropics of Australia. J Environ Manage 2005; 75: 1-9.

[150] Birol E, Karousakis K, Koundouri P. Using a choice experiment to account for preference heterogeneity in wetland attributes: the case of Cheimaditida wetland in Greece. Ecol Econ 2006; 60: 145-56.

[151] Vacik H, Lexer JM. Application of a spatial decision support system in managing the protection forests of Vienna for sustained yield water resources. For Ecol Manage 2001; 143: 65-76.

[152] Huth A, Drechsler M, Kohler P. Multicriteria evaluation of simulated logging scenarios in a tropical rain forest. J Environ Manage 2004; 71: 321-33

[153] Huth A, Drechsler M, Köhler P. Using multicriteria decision analysis and a forest growth model to assess impacts of tree harvesting in Dipterocarp lowland rain forests. For Ecol Manage 2005; 207: 215-32

[154] Wattage P, Mardle S. Stakeholder preferences towards conservation versus development for a wetland in Sri Lanka. J Environ Manage 2005; 77: 122-32. 
[155] Kangas J, Kangas A. Multicriteria approval and SMAA-O in natural resources decision analysis with both ordinal and cardinal criteria. J Multi-Crit Decis Anal 2003; 12: 3-15.

[156] Mendoza GA, Prabhu R. Qualitative multi-criteria approaches to assessing indicators of sustainable forest resource management. For Ecol Manage 2003; 174: 329-43.

[157] Adrianto L, Matsuda Y, Sakuma Y. Assessing local sustainability of fisheries system: a multi-criteria participatory approach with the case of Yoron Island, Kagoshima prefecture, Japan. Mar Policy 2005; 29: 9-23.

[158] Marttunen M, Suomalainen M. Participatory and multiobjective development of watercourse regulation creation of regulation alternatives from stakeholders' preferences. J Multi-Crit Dec Anal 2005; 13: 29-49.

[159] Pykäläinen J, Hiltunen V, Leskinen P. Complementary use of voting methods and interactive utility analysis in participatory strategic forest planning: experiences gained from western Finland. Can J For Res 2007; 37: 853-65.

[160] Raff C. Autonomous development: humanizing the landscape. London: Zed 1996.
[161] Buchy M, Hoverman S. Understanding public participation in forest planning: a review. For Policy Econ 2000; 1: 15-25.

[162] United Nations. Indicators of sustainable development: guidelines and methodologies. $3^{\text {rd }}$ ed. New York 2007.

[163] Burley J. In: Sheppard SRJ, Harshaw WW, Eds. Forests and landscapes: linking ecology, sustainability and aesthetics. New York, CABI Publishing 2001; 95-102.

[164] Leskinen LA, Laurén K, Järvinen S, Sairinen R, Leskinen P. Sosiaalisten ja kulttuuristen vaikutusten ja kestävyyden arvioiminen metsätaloudessa ja metsien monimuotoisuuden turvaamisessa. Working Papers of the Finnish Forest Research Institute. Finnish Forest Research Institute 2008.

[165] Harshaw HW, Sheppard SRJ, Lewis JL. A review and synthesis of social indicators for sustainable forest management. BC $\mathrm{J}$ and Ecos Manage 2007, 8: 17-36.

[166] DeSanctis G, Galluple RB. A foundation for the study of group decision support systems. Manage Sci 1987; 33: 598-600.

[167] Sipilä M, Tyrväinen L. Evaluation of collaborative urban forest planning in Helsinki, Finland. Urban For Urban Green 2005; 4: 112 .

(C) Myllyviita et al.; Licensee Bentham Open.

This is an open access article licensed under the terms of the Creative Commons Attribution Non-Commercial License (http://creativecommons.org/licenses/by$\mathrm{nc} / 3.0 /$ ) which permits unrestricted, non-commercial use, distribution and reproduction in any medium, provided the work is properly cited. 